\title{
Prevalence of Eating Disorders in Adolescents Girls in Srinagar City
}

\author{
Dr. Naheed Vaida \\ Associate Professor Institute of Home Science University of Kashmir Hazratbal Srinagar-190006
}

\begin{abstract}
The present study entitled "Prevalence of Eating Disorders in Adolescent girls in Srinagar city" was carried out in Srinagar. 100 adolescent girls from 5 schools, 20 from each, were selected randomly for the study. They were assessed through a structured questionnaire based on DSM IV criteria. It was found that the prevalence of eating disorders in our part of the world is very less as compared to the west as none of the adolescent girls in our study satisfied all the four criteria necessary for the diagnosis of anorexia nervosa or bulimia nervosa. However, about 30\% of the adolescent girls satisfied two and 6\% satisfied up to three criterias. As per the results obtained it was found that the mean weight of the sample was $47.90 \mathrm{~kg}$ with standard deviation of 6.36. Twenty three percent (23\%) of the sample had weight less than $80 \%$ of expected for their age i.e. were malnourished. Although the prevalence of the eating disorders is very less in our city but the adolescent girls are becoming body conscious and many are at risk of developing eating disorder. As in the west no significant relation was found between family income and eating disorders although lower income groups showed higher prevalence of different criteria of eating disorders. Likewise there was no significant relation between eating disorder risk factors and features like age group, fathers and mothers qualification. Only one criterion, that is importance of being thinner than one's friends, showed statistically significant relation with age, qualification of parents etc. As many of the adolescent girls are at high risk of developing eating disorders, it seems to be right time to take preventive measures. Health education seems to be the best way to counter this problem. Both parents and children need to be educated. Mass media has to play a major role in bringing awareness regarding the problem.
\end{abstract}

Key words: Eating disorder, Adolescents, Anorexia nervosa, BMI.

\section{Introduction}

Adolescence is a period of transition from childhood to adulthood. It is a stage of life that begins at puberty. In girls the puberty is typically reached at 12 and 13, while boys reach it at 14 and 15 years of age. Adolescence is a period of maturation for both mind and body. The child develops gradually the ability to reason, problem solving skills, and attains emotional maturity. During it along with the physical growth, emotional and intellectual development is also rapid. Adolescence is a critical period of nutritional care. There is a high correlation reported between malnutrition during adolescence and early onset of degenerative diseases like, hyperlipidemia, cardiovascular problems, diabetes, and obesity in older ages. Thus in order to delay the early onset of degenerative diseases in adulthood it is important that wrong dietary and life style practices are checked at this age so that these unhealthy practices do not pass into adulthood. There is accumulating evidence that active lifestyle developed in childhood and adolescence continues into adulthood (Sidhu, 2006).

Adolescence marks a major shift from protective parental care into adult life. During this period, adolescents try to build self identity, feel uncomfortable with their rapidly changing bodies, and become very conscious about their appearances and feel pressure to be thin or to look a certain way.

Adolescence is thought to be the period during which distortion of body image may be initiated. Therefore, adolescence is a crucial time for the development of a realistic body image. Dissatisfaction with one's body becomes so prevalent that it is considered to be a normal part of female experience. The influence of celebrities impacts their food habits, their dressing style and the social company with which they associate themselves. There is also tremendous impact of mass media on this age group.

Adolescence is one of the most challenging periods in human development. Almost every organ in the body grows during this period. There is a noticeable increase in height, weight and in the development of the secondary sexual characteristics. The nutritional requirements increase during this period as nutritional status and physical growth are interdependent.

In adolescent girls the adequate nutrition is a prerequisite for achieving optimal growth and development. However many teenage girls rarely relate today's food habits to tomorrow's health. They try to attain desirable body shape and ideal body weight by imitating a fashion model or a celebrity. This forces the adolescent's girls to purposely starve themselves to maintain such a lean body by reducing the food intake. Many girls aspire to attain a body shape which is thinner than their current shape. Such girls often miss meals at home, skip breakfast and lunch altogether. Fear of gaining weight may lead to overly restrictive eating habit 
(Killen et al 1998). As desire to be thinner increases some teens resort to self induced vomiting or laxative use to control their weight, whereas during adolescence the adolescent needs to eat in adequate amounts and at regular intervals of time. Such anomalies in nutritional intake have negative effects on the development. It reduces the capability to learn and work at maximum productivity. This affects the sexual maturity, growth and prevents attainment of normal bone strength and the development of healthy teeth.

In today's society where weight management has become one of the main issues related to one's appearance, it's important to understand that the problems associated with too much deviations on either side from the appropriate range of body weight increases the risk of health problems. Obsession with slimming, especially in the adolescent age group may result in anorexia nervosa, bulimia nervosa and other eating disorders. Hence the present study i.e., "Prevalence of Eating disorders among adolescent girls in Srinagar City" is an attempt made to figure out the prevalence of eating disorders among Kashmiri adolescent girls.

\section{Objectives}

- To figure out eating disorders among adolescent girls.

- To determine the impact of parent's income on the prevalence of eating disorders.

- To assess the nutritional status of the adolescents.

- To determine the wrong dietary patterns/eating habits among adolescent girls.

- To work out remedial measures to modify the eating disorder.

\section{Review Of Literature}

Stuart \& Laraia (2001) define eating disorders as the use of food to satisfy unmet emotional needs, to moderate stress, and to provide rewards or punishments. Further, "the inability to regulate eating habits and the frequent tendency to overuse or under use food interferes with biological, psychological, and socio-cultural integrity".

A study by Lowe et. al. (1985) regarding eating attitudes in 1514 Auckland school girls (13-17 years old) found that 14 percent of this population demonstrated behaviours that were suggestive of potential eating disorders. Garner et al (1985) carried out a survey in order to find similarities among bulimic groups selected by different weights and weight histories. These groups were similar in terms of attitudes toward food, eating and body dissatisfaction as well as other traits which have been identified as relevant to eating disorder patients. Results also indicated that the referral patterns of patients with different weight histories have changed over time; previously, most patients had anorexia nervosa either currently or historically but more recently many patients are presenting with symptoms of equal severity but with no history of anorexia nervosa.

Kaltiala et al in a report (1989) writes about the Bulimia and bulimic behaviour in middle adolescents. In total, 4453 girls and 4334 boys aged 14 to 16 years participated. Bulimioa was detected in $1.8 \%$ of girls and $0.3 \%$ of boys. Bulimic eating behavior was reported by $14.4 \%$ of subjects. Bulimia was associated with being bullied by peers and higher than average weight in both sexes. Bulimia and bulimic eating behavior appear to be more common than was previously thought in idle adolescence, and also among boys. Bulima deserves more attention in younger age groups than main risk groups so far considered.

A study conducted by Grigg et al (2002) showed that over one-third (36\%) of the total sample had used at least one "extreme" dieting method in the past month, i.e., "crash" dieting, fasting, slimming tablets, diuretics, laxatives, and/or cigarettes to lose weight. Of the total sample, $77 \%$ wanted to lose weight and $51 \%$ had tried to lose weight in the past month. Motivating factors for disordered eating and unhealthy dieting behaviours were peer and media pressure and the perception that extreme dieting strategies were harmless.

In a five year longitudinal study by Neumark-Sztaineret al (2006) it was revealed that dieting and unhealthy weight-control behaviours predict outcomes related to obesity and eating disorders. A shift away from dieting and drastic weight-control measures toward the long-term implementation of healthful eating and physical activity behaviours is needed to prevent obesity and eating disorders in adolescents.

Alantar (2008) in his study observed that instability in child's earliest relationship with caregivers may lead to eating disorders. From this perspective, since food consumption usually replaces parental affection, the patient believes that she/he can control and arrange it both qualitatively and quantitatively. Eating disordered individuals are considered to fail frequently in establishing emotional communication with the persons they attached and also to have built insecurity.

Sonja et al (2011) found that eating disorders and sub threshold eating conditions are prevalent in the general adolescent population. Their impact is demonstrated by generally strong associations with other psychiatric disorders, role impairment and suicidality. The unmet treatment needs in the adolescent population place these disorders as important public health concerns.

Ruth et al (1992) found that when applying stringent diagnostic procedure and matching criteria, IDDM girls do not evidence on elevated prevalence of eating disorder symptoms. However, those IDDM 
patients who did not report symptoms may have a high risk group for the development of an eating disorder and should be followed prospectively.

Mammen et al (2007) in their study found that overall prevalence of eating disorders was lower than the western data that has focused on anorexia and bulimia nervosa but was comparable with most of the nonwestern literature. The prevalence of eating disorders was $1.25 \%$ Psychogenic vomiting was the commonest eating disorders and anorexia nervosa the emerging eating disorder. The common co-morbidities were depression, intellectual disability and also dissociative disorder.

\section{Materials And Methods}

The study was carried out in Srinagar city where educational institutions are being established at a rapid rate. The information was collected by visiting some of the high and senior secondary schools from where the girl adolescents were selected for the present study. This descriptive study consisted of three high schools and two senior secondary schools which were randomly selected among various schools present in the Srinagar city.

The population under study consists of adolescent girls from different schools. The population being homogenous as the entire populations live within the boundaries of Srinagar city. Simple random sampling was adopted to work out the sample from the population. However, the girls suffering from any disease were excluded from the study. A rough questionnaire was prepared and a pilot survey was conducted for testing purpose of questionnaire and on the basis of responses and suggestions of respondents, final version of questionnaire was designed.

The data collected was self-reported by the students. All the information was collected honestly and free of any duplicity. Finally, the results were computed and the data was analyzed accordingly. It included the weight, height and BMI of the sample. Following the completion of the questionnaires, their body mass indexes (BMIs) were calculated by measuring their heights and weights. BMI, computed as weight in kilograms divided by the square of height in meters (body mass $/ h^{2} \operatorname{sght}^{2}=\mathrm{kg} / \mathrm{m}^{2}$ ). Each student's body weight was measured with domestic scales and height with a meter rule.

The data collected was carefully scrutinized and condensed in the form of master chart and then tabulated in terms of statistical tools to represent in a meaningful way. Chi-square and Fisher T tests were used for qualitative and quantitative data respectively, to determine statistical significance of results obtained.

\section{A: TABLES:}

\section{Results And Findings}

Table 1 : Distribution Of Respondents As Per Their Dislike For Body.

\begin{tabular}{|l|l|l|l|l|l|}
\hline $\begin{array}{l}\text { AGE } \\
\text { GROUP (IN } \\
\text { YEARS) }\end{array}$ & AGREE & DISAGREE & $\begin{array}{l}\text { SOMETIMES } \\
\text { AGREE }\end{array}$ & UNDECIDED & TOTAL \\
\hline $13-14$ & $0(0 \%)$ & $3(75 \%)$ & $1(25 \%)$ & $0(0 \%)$ & 4 \\
\hline $14-15$ & $3(12 \%)$ & $19(76 \%)$ & $1(4 \%)$ & $2(8 \%)$ & 25 \\
\hline $15-16$ & $6(14.3 \%)$ & $33(78.6 \%)$ & $1(2.4 \%)$ & $2(4.8 \%)$ & 42 \\
\hline $16-17$ & $1(14.3 \%)$ & $6(85.7 \%)$ & $0(0 \%)$ & $0(0 \%)$ & 7 \\
\hline $17-18$ & $3(23.1 \%)$ & $10(76.9 \%)$ & $0(0 \%)$ & $0(0 \%)$ & 13 \\
\hline $18-19$ & $3(33.3 \%)$ & $6(66.7 \%)$ & $0(0 \%)$ & $0(0 \%)$ & 9 \\
\hline TOTAL & 16 & 77 & 3 & 4 & 100 \\
\hline
\end{tabular}

Table No.1 shows the percentage of the respondents of different age groups who disliked their body. Maximum (33.3\%) were seen in the age group of 18 to 19 years while as none of the respondent in the age group of 13-14 years had a dislike for her body. The dislike increased with increasing age but was not statistically significant.

Table 2: Age Wise Distribution Of Respondents As Per Their Desire For Thinness.

\begin{tabular}{|l|l|l|l|l|l|}
\hline $\begin{array}{l}\text { AGE } \\
\text { GROUP } \\
\text { (IN } \\
\text { YEARS) }\end{array}$ & AGREE & DISAGREE & $\begin{array}{l}\text { SOMETIMES } \\
\text { AGREE }\end{array}$ & UNDECIDED & TOTAL \\
\hline $13-14$ & $0(0 \%)$ & $4(100 \%)$ & $0(0 \%)$ & $0(0 \%)$ & 4 \\
\hline $14-15$ & $4(16 \%)$ & $19(76 \%)$ & $2(8 \%)$ & $0(0 \%)$ & 25 \\
\hline $15-16$ & $23(54.8 \%)$ & $19(45.2 \%)$ & $0(0 \%)$ & $0(0 \%)$ & 42 \\
\hline $16-17$ & $6(85.7 \%)$ & $1(14.3 \%)$ & $0(0 \%)$ & $0(0 \%)$ & 7 \\
\hline $17-18$ & $6(46.2 \%)$ & $7(53.8 \%)$ & $0(0 \%)$ & $0(0 \%)$ & 13 \\
\hline $18-19$ & $3(33.3 \%)$ & $6(66.7 \%)$ & $0(0 \%)$ & $0(0 \%)$ & 9 \\
\hline TOTAL & 42 & 56 & 2 & 0 & 100 \\
\hline
\end{tabular}




\section{$X^{2}=18.34$ (critical value $=15.08$ at 0.01 level of significance)}

Table 2 indicates the age wise distribution of the respondents who wanted to be thinner than their friends. A maximum (85.7\%) percent of the sample belonging to 16-17 years age group wanted to be thinner than their friends, followed by 54\% in 15-16 years age group. None of the respondents in the age group of 13-14 years agreed that they had a desire to be thin. The correlation was statistically significant.

Table 3: Desire Of Thinness Viz A Viz Monthly Family Income

\begin{tabular}{|l|l|l|l|l|l|}
\hline $\begin{array}{l}\text { MONTHLY } \\
\text { INCOME } \\
\text { (IN } \\
\text { RUPEES) }\end{array}$ & AGREE & DISAGREE & $\begin{array}{l}\text { SOMETIMES } \\
\text { AGREE }\end{array}$ & UNDECIDED & TOTAL \\
\hline$<10,000$ & $11(84.6 \%)$ & $2(15.4 \%)$ & $0(0 \%)$ & $0(0 \%)$ & 13 \\
\hline $\begin{array}{l}10,000- \\
20,000\end{array}$ & $8(33.3 \%)$ & $15(62.5 \%)$ & $1(4.2 \%)$ & $0(0 \%)$ & 24 \\
\hline $\begin{array}{l}20,000- \\
30,000\end{array}$ & $15(45.5 \%)$ & $17(51.5 \%)$ & $1(3 \%)$ & $0(0 \%)$ & 33 \\
\hline $\begin{array}{l}30,000- \\
40,000\end{array}$ & $4(33.3 \%)$ & $8(66.7 \%)$ & $0(0 \%)$ & $0(0 \%)$ & 12 \\
\hline $\begin{array}{l}40,000- \\
50,000\end{array}$ & $1(12.5 \%)$ & $7(87.5 \%)$ & $0(0 \%)$ & $0(0 \%)$ & 8 \\
\hline$>50,000$ & $3(30 \%)$ & $7(70 \%)$ & $0(0 \%)$ & $0(0 \%)$ & 10 \\
\hline TOTAL & 42 & 56 & 2 & 0 & 100 \\
\hline \multicolumn{7}{|l|}{$\mathrm{X}^{2}=14.31$ (critical value $=11.07$ at 0.05 level of significance) } & \\
\hline
\end{tabular}

Table 3 reveals that $84.6 \%$ respondents having family income $<$ Rs. 10,000 had a desire to be thinner than their friends. The correlation was statistically significant.

Table 4: Age Wise Distribution Of Respondents Who Diet To Reduce Weight

\begin{tabular}{|l|l|l|l|l|l|}
\hline $\begin{array}{l}\text { AGE } \\
\text { GROUP (IN } \\
\text { YEARS) }\end{array}$ & AGREE & DISAGREE & SOMETIMES AGREE & UNDECIDED & TOTAL \\
\hline $13-14$ & $0(0 \%)$ & $4(100 \%)$ & $0(0 \%)$ & $0(0 \%)$ & 4 \\
\hline $14-15$ & $3(12 \%)$ & $21(84 \%)$ & $1(4 \%)$ & $0(0 \%)$ & 25 \\
\hline $15-16$ & $5(11.9 \%)$ & $36(85.7 \%)$ & $1(2.4 \%)$ & $0(0 \%)$ & 42 \\
\hline $16-17$ & $0(0 \%)$ & $7(100 \%)$ & $0(0 \%)$ & $0(0 \%)$ & 7 \\
\hline $17-18$ & $0(0 \%)$ & $9(69.2 \%)$ & $4(30.8 \%)$ & $0(0 \%)$ & 13 \\
\hline $18-19$ & $3(33.3 \%)$ & $6(66.7 \%)$ & $0(0 \%)$ & $0(0 \%)$ & 9 \\
\hline TOTAL & 11 & 83 & 6 & 0 & 100 \\
\hline
\end{tabular}

The above table reveals that desire to diet increased with age. Maximum (33.3\%) respondents who had a desire to resort to dieting in order to reduce weight fell in the age group of 18-19 years. This is understandable because as the adolescent's age goes on increasing, he/she becomes more conscious of his/her looks.

Table 5: Dieting Viz A Viz Monthly Family Income

\begin{tabular}{|l|l|l|l|l|l|}
\hline $\begin{array}{l}\text { MONTHLY } \\
\text { INCOME (IN } \\
\text { RUPEES) }\end{array}$ & AGREE & DISAGREE & SOMETIMES AGREE & UNDECIDED & TOTAL \\
\hline$<10,000$ & $2(15.4 \%)$ & $11(84.6 \%)$ & $0(0 \%)$ & $0(0 \%)$ & 13 \\
\hline $\begin{array}{l}10,000- \\
20,0000\end{array}$ & $2(8.3 \%)$ & $20(83.4 \%)$ & $2(8.3 \%)$ & $0(0 \%)$ & 24 \\
\hline $\begin{array}{l}20,000- \\
30,000\end{array}$ & $4(12.1 \%)$ & $27(81.8 \%)$ & $2(6.1 \%)$ & $0(0 \%)$ & 33 \\
\hline $\begin{array}{l}30,000- \\
40,000\end{array}$ & $1(8.3 \%)$ & $10(83.4 \%)$ & $1(8.3 \%)$ & $0(0 \%)$ & 12 \\
\hline $\begin{array}{l}40,000- \\
50,000\end{array}$ & $0(0 \%)$ & $8(100 \%)$ & $0(0 \%)$ & $0(0 \%)$ & 8 \\
\hline$>50,000$ & $2(20 \%)$ & $7(70 \%)$ & $1(10 \%)$ & $0(0 \%)$ & 10 \\
\hline TOTAL & 11 & 83 & 6 & 0 & 100 \\
\hline
\end{tabular}


Table 5 reveals that dieting is most prevalent (20\%) in respondents whose total family income was more than Rs.50,000 showing that adolescents belonging to high income group are more conscious of their bodies.

Table 6: Age Wise Distribution Of The Respondents Who Binge Eat

\begin{tabular}{|l|l|l|l|l|l|}
\hline $\begin{array}{l}\text { AGE } \\
\text { GROUP (IN } \\
\text { YEARS) }\end{array}$ & AGREE & DISAGREE & SOMETIMES AGREE & UNDECIDED & TOTAL \\
\hline $13-14$ & $1(25 \%)$ & $3(75 \%)$ & $0(0 \%)$ & $0(0 \%)$ & 4 \\
\hline $14-15$ & $1(4 \%)$ & $20(80 \%)$ & $2(8 \%)$ & $2(8 \%)$ & 25 \\
\hline $15-16$ & $9(21.4 \%)$ & $31(73.8 \%)$ & $2(4.8 \%)$ & $0(0 \%)$ & 42 \\
\hline $16-17$ & $1(14.3 \%)$ & $6(85.7 \%)$ & $0(0 \%)$ & $0(0 \%)$ & 7 \\
\hline $17-18$ & $2(\%) 15.4$ & $10(76.9 \%)$ & $1(7.7 \%)$ & $0(0 \%)$ & 13 \\
\hline $18-19$ & $0(0 \%)$ & $6(66.7 \%)$ & $3(33.3 \%)$ & $0(0 \%)$ & 9 \\
\hline TOTAL & 14 & 76 & 8 & 2 & 100 \\
\hline
\end{tabular}

Table 6 reveals highest percentage i.e. $21.4 \%$ of the respondents in the 15-16 years age group binge eat while none in 18-19 years age show such features.

Table 7: Binge Eating Viz A Viz Monthly Family Income

\begin{tabular}{|l|l|l|l|l|l|}
\hline $\begin{array}{l}\text { MONTHLY } \\
\text { INCOME (IN } \\
\text { RUPEES) }\end{array}$ & AGREE & DISAGREE & SOMETIMES AGREE & UNDECIDED & TOTAL \\
\hline$<10,000$ & $0(0 \%)$ & $13(100 \%)$ & $0(0 \%)$ & $0(0 \%)$ & 13 \\
\hline $\begin{array}{l}10,000- \\
20,0000\end{array}$ & $4(16.6 \%)$ & $18(75 \%)$ & $1(4.2 \%)$ & $1(4.2 \%)$ & 24 \\
\hline $\begin{array}{l}20,000- \\
30,000\end{array}$ & $4(12.1 \%)$ & $24(72.7 \%)$ & $5(15.2 \%)$ & $0(0 \%)$ & 33 \\
\hline $\begin{array}{l}30,000- \\
40,000\end{array}$ & $1(8.3 \%)$ & $11(91.7 \%)$ & $0(0 \%)$ & $0(0 \%)$ & 12 \\
\hline $\begin{array}{l}40,000- \\
50,000\end{array}$ & $3(37.5 \%)$ & $4(50 \%)$ & $1(12.5 \%)$ & $0(0 \%)$ & 8 \\
\hline$>50,000$ & $2(20 \%)$ & $6(60 \%)$ & $1(10 \%)$ & $1(10 \%)$ & 10 \\
\hline TOTAL & 14 & 76 & 8 & 2 & 100 \\
\hline
\end{tabular}

Table 7 reveals that the total family income of Rs.40,000-50,000 show highest percentage (37.5\%) of respondents with features of binge eating, while > Rs 50,000 group showed percentage of $20 \%$ followed by $16.6 \%$ in Rs. 10,000-20,000 subgroup.

Table 8: Age Wise Distribution of The Sample On The Basis Of Lack Of Control Over Eating

\begin{tabular}{|l|l|l|l|l|l|}
\hline $\begin{array}{l}\text { AGE GROUP } \\
\text { (IN YEARS) }\end{array}$ & AGREE & DISAGREE & SOMETIMES AGREE & UNDECIDED & TOTAL \\
\hline $13-14$ & $0(0 \%)$ & $4(100 \%)$ & $0(0 \%)$ & $0(0 \%)$ & 4 \\
\hline $14-15$ & $1(4 \%)$ & $23(92 \%)$ & $1(4 \%)$ & $0(0 \%)$ & 25 \\
\hline $15-16$ & $4(9.5 \%)$ & $37(88.1 \%)$ & $1(2.4 \%)$ & $0(0 \%)$ & 42 \\
\hline $16-17$ & $0(0 \%)$ & $7(100 \%)$ & $0(0 \%)$ & $0(0 \%)$ & 7 \\
\hline $17-18$ & $2(15.4 \%)$ & $11(84.6 \%)$ & $0(0 \%)$ & $0(0 \%)$ & 13 \\
\hline $18-19$ & $0(0 \%)$ & $9(100 \%)$ & $0(0 \%)$ & $0(0 \%)$ & 9 \\
\hline TOTAL & 7 & 91 & 2 & 0 & 100 \\
\hline
\end{tabular}

Table 8 reveals that most of the respondents had control over eating. Most of the respondents who lack control were in the age group of 17-18 year (15.4\%) and 15-16 years (9.5\%) and none of them was in 13-14 year, 16-17 year and 18-19 year groups. 
Table 9 : Lack of Control Over Eating With Different Family Income

\begin{tabular}{|l|l|l|l|l|l|}
\hline $\begin{array}{l}\text { MONTHLY } \\
\text { INCOME (IN } \\
\text { RUPEES) }\end{array}$ & AGREE & DISAGREE & SOMETIMES AGREE & UNDECIDED & TOTAL \\
\hline$<10,000$ & $0(0 \%)$ & $13(100 \%)$ & $0(0 \%)$ & $0(0 \%)$ & 13 \\
\hline $\begin{array}{l}10,000- \\
20,0000\end{array}$ & $2(8.3 \%)$ & $21(87.5 \%)$ & $1(4.2 \%)$ & $0(0 \%)$ & 24 \\
\hline $\begin{array}{l}20,000- \\
30,000\end{array}$ & $1(3 \%)$ & $32(97 \%)$ & $0(0 \%)$ & $0(0 \%)$ & 33 \\
\hline $\begin{array}{l}30,000- \\
40,000\end{array}$ & $2(16.7 \%)$ & $9(75 \%)$ & $1(8.3 \%)$ & $0(0 \%)$ & 12 \\
\hline $\begin{array}{l}40,000- \\
50,000\end{array}$ & $1(12.5 \%)$ & $7(87.5 \%)$ & $0(0 \%)$ & $0(0 \%)$ & 8 \\
\hline$>50,000$ & $1(10 \%)$ & $9(90 \%)$ & $0(0 \%)$ & $0(0 \%)$ & 10 \\
\hline TOTAL & 7 & 91 & 2 & 0 & 100 \\
\hline
\end{tabular}

Table 9 reveals that a small percentage of respondents lack control over eating. Highest (16.7\%) was in the family income of Rs.30,000-40,000 group followed by $12.5 \%$ in $40=50000$ and none of them was in Rs. 10,000 group.

Table 10 : Age Wise Distribution Of Respondents Who Vomit After Eating

\begin{tabular}{|l|l|l|l|l|l|}
\hline $\begin{array}{l}\text { AGE GROUP } \\
\text { (IN YEARS) }\end{array}$ & AGREE & DISAGREE & SOMETIMES AGREE & UNDECIDED & TOTAL \\
\hline $13-14$ & $0(0 \%)$ & $3(75 \%)$ & $1(25 \%)$ & $0(0 \%)$ & 4 \\
\hline $14-15$ & $0(0 \%)$ & $22(88 \%)$ & $3(22 \%)$ & $0(0 \%)$ & 25 \\
\hline $15-16$ & $1(2.4 \%)$ & $30(71.4 \%)$ & $11(26.2 \%)$ & $0(0 \%)$ & 42 \\
\hline $16-17$ & $0(0 \%)$ & $7(100 \%)$ & $0(0 \%)$ & $0(0 \%)$ & 7 \\
\hline $17-18$ & $0(0 \%)$ & $9(69.2 \%)$ & $4(30.8 \%)$ & $0(0 \%)$ & 13 \\
\hline $18-19$ & $0(0 \%)$ & $8(88.9 \%)$ & $0(0 \%)$ & $1(11.1 \%)$ & 9 \\
\hline TOTAL & 1 & 79 & 19 & 1 & 100 \\
\hline
\end{tabular}

Table 10 reveals that vomiting after eating was very rare. Only a single respondent who was in the age group of 15-16 years used to vomit after eating and belonged to family income of Rs.10,000-20,000.

Table 11 : BMI Distribution According To Age Group

\begin{tabular}{|l|l|l|l|l|}
\hline $\begin{array}{l}\text { AGE } \\
\text { GROUP } \\
\text { IN } \\
\text { YEARS })\end{array}$ & $\begin{array}{l}\text { NO. OF } \\
\text { RESPONDENTS }\end{array}$ & PERCENTAGE & $\begin{array}{l}\text { MEAN BMI } \\
\left(\mathrm{kg} / \mathrm{m}^{2}\right)\end{array}$ & $\begin{array}{l}\text { EXPECTED } \\
\text { BMI }\left(\mathrm{kg} / \mathrm{m}^{2}\right)\end{array}$ \\
\hline $13-14$ & 4 & $4 \%$ & 18.14 & 19 \\
\hline $14-15$ & 25 & $25 \%$ & 18.97 & 19.7 \\
\hline $15-16$ & 42 & $42 \%$ & 19.45 & 20.2 \\
\hline $16-17$ & 7 & $7 \%$ & 20.07 & 20.7 \\
\hline $17-18$ & 13 & $13 \%$ & 20.17 & 21.1 \\
\hline $18-19$ & 9 & $9 \%$ & 21.14 & 21.4 \\
\hline
\end{tabular}

Table 11 reveals that BMI in all age groups was slightly lower than expected for that age group.

Table 12: BMI Distribution According To Monthly Family Income

\begin{tabular}{|l|l|l|l|l|}
\hline $\begin{array}{l}\text { MONTHLY } \\
\text { INCOME } \\
\text { (IN } \\
\text { RUPEES) }\end{array}$ & $\begin{array}{l}\text { NO. OF } \\
\text { RESPONDENTS }\end{array}$ & PERCENTAGE & $\begin{array}{l}\text { MAEN BMI } \\
\left(\mathrm{kg} / \mathrm{m}^{2}\right)\end{array}$ & $\begin{array}{l}\text { EXPECTED } \\
\text { BMI } \\
\left(\mathrm{kg} / \mathrm{m}^{2}\right)\end{array}$ \\
\hline$<10,000$ & 13 & $13 \%$ & 19.74 & 20.26 \\
\hline $\begin{array}{l}10,000- \\
20,0000\end{array}$ & 24 & $24 \%$ & 18.98 & 20.26 \\
\hline $\begin{array}{l}20,000- \\
30,000\end{array}$ & 33 & $33 \%$ & 19.16 & 20.26 \\
\hline
\end{tabular}




\begin{tabular}{|l|l|l|l|l|}
\hline $\begin{array}{l}30,000- \\
40,000\end{array}$ & 12 & $12 \%$ & 18.58 & 20.26 \\
\hline $\begin{array}{l}40,000- \\
50,000\end{array}$ & 8 & $8 \%$ & 18.43 & 20.26 \\
\hline$>50,000$ & 10 & $10 \%$ & 20.02 & 20.26 \\
\hline
\end{tabular}

Table 12 reveals that mean BMI of all groups based on total family income was less than mean expected BMI of the whole sample. The difference was more conspicuous in the income group Rs.40,000-50,000.

\section{B: FIGURES}

\section{Figure No. 1: Mean Weight According To Age}

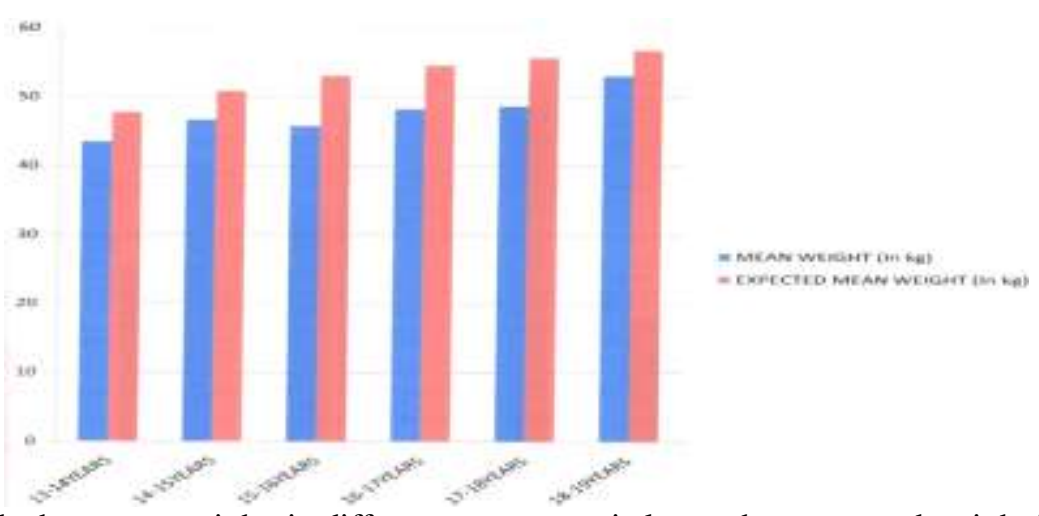

Above figure reveals that mean weight, in different age groups is lower than expected weight in each group. The difference being more prominent among adolescents who belonged to the age group of 15-16 years.

\section{Figure No. 2:Mean Height (In Meters) According To Age:}

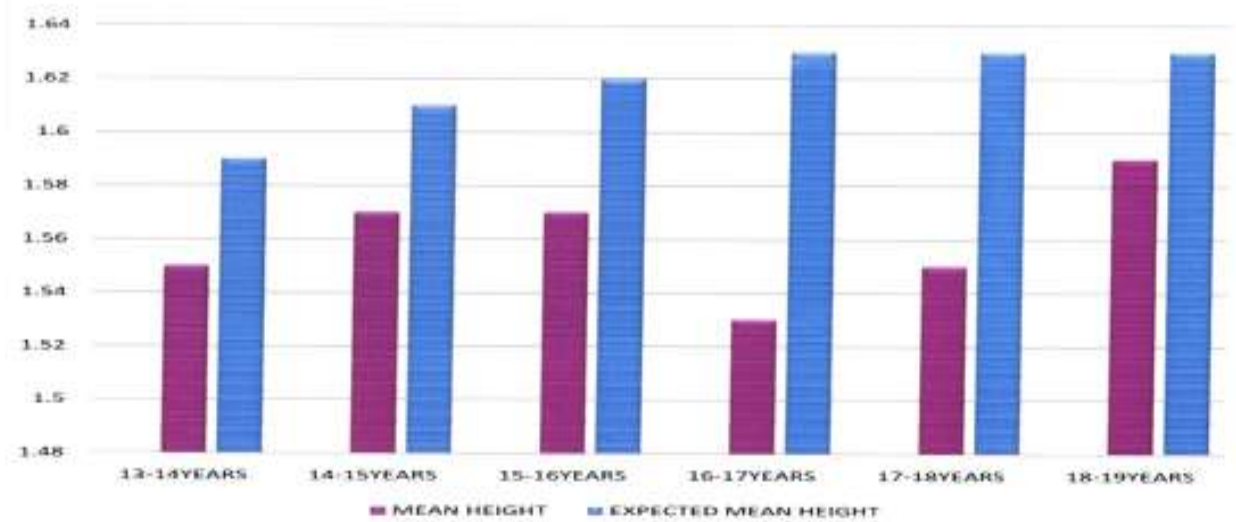

Above figure reveals that mean height, in different age groups is lower than expected for each age group. The difference being more prominent among adolescents in 16-17 years.

\section{Figure No. 3:Showing The Percentage Of The Students Who Adopt Various Appetite Control Measures}

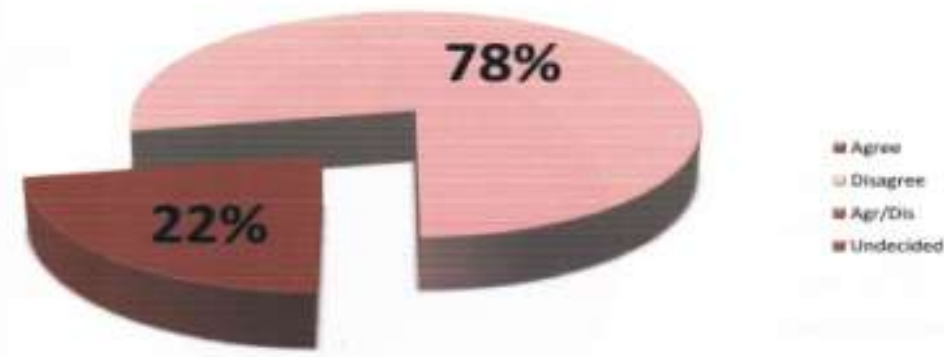


On the basis of the results given in the chart, it is deduced that $22 \%$ of the students resorted to junk foods, candies, gums or drank lots of water and coffee in order to skip proper meals. $78 \%$ of the students take proper meals.

Figure No. 4:Showing Percentage Of The Students Who Skip Their Meals To Control Their Weight

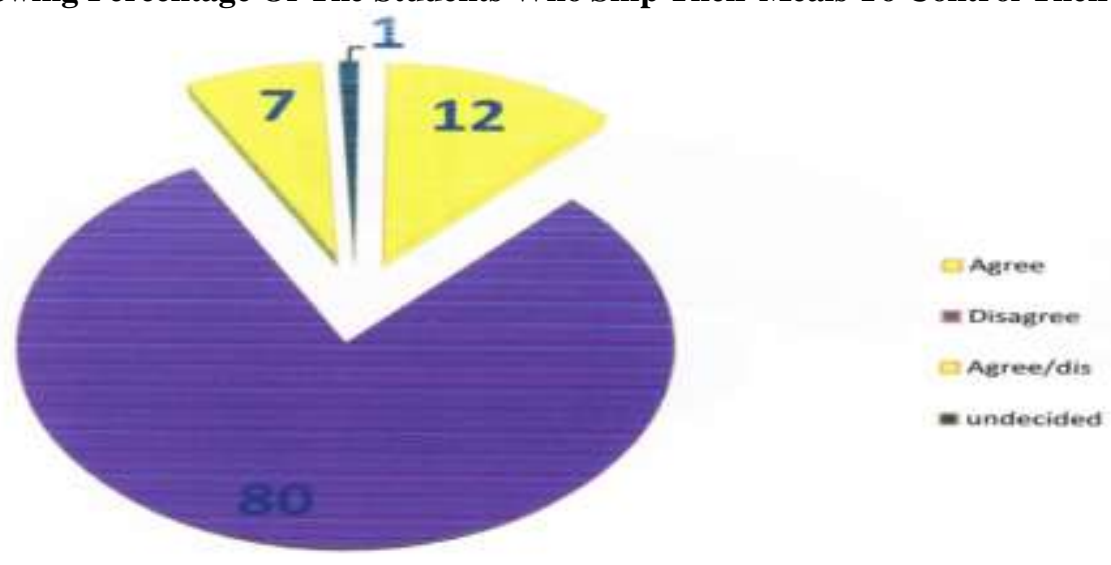

Huge majority $(80 \%)$ of the respondents did not skip their meals to control weight however $12 \%$ of them resorted to skipping meals as an attempt to control weight. $7 \%$ occasionallly skipped meals to control their weight and $1 \%$ were not sure.

\section{Figure No. 5:Showing The Percentage Of Students Who Over-Estimate The Size Or Fatness Of Their} Bodies

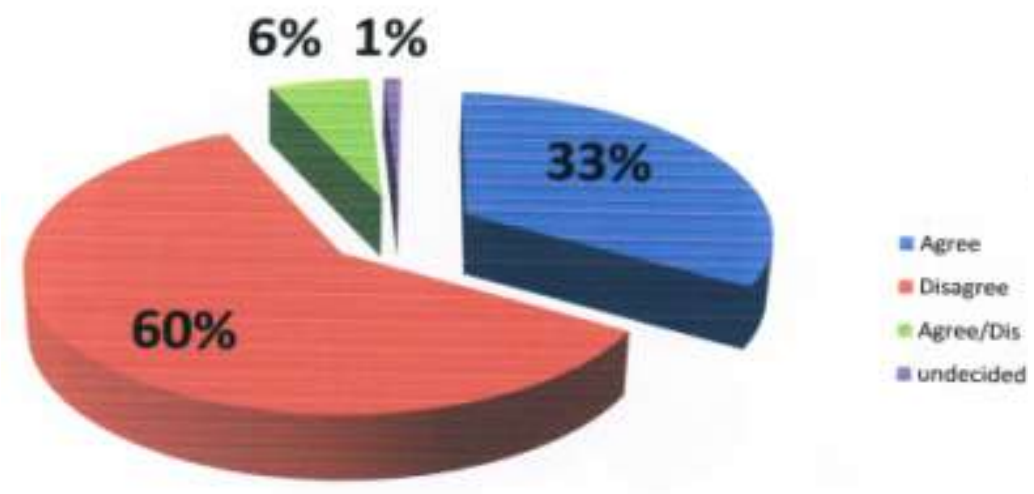

The above charts reveal that $33 \%$ of the girls in the selected sample had distorted body image i.e., they think they are fat even when they are thin and $60 \%$ of the respondents disagreed and thought their bodies to be proper. $6 \%$ occasionally felt so, while as $1 \%$ were not sure.

Figure No. 6:Showing The Percentage Of The Students Who Plan To Exercise If There Is Weight Gain wAgree $=$ Disagree $=$ Agree/Dis $=$ undecided

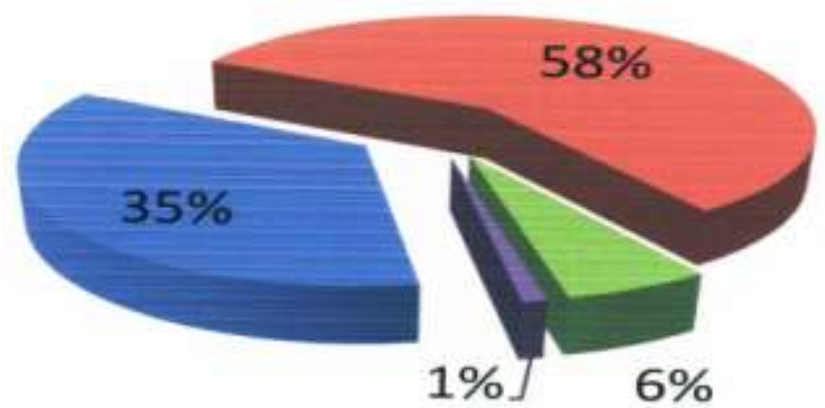

$5 \%$ of the sample registered that they would exercise if they gain weight and $58 \%$ do not want to exercise even if the weight is gained while as $6 \%$ occasionally thought to exercise in case they gain weight. 


\section{Discussion}

One of the most stressful times in a person's life is when he/she enters into adolescence. This is a time when people begin to discover who they are, they are becoming more independent, they are establishing friendships, and their bodies start developing. Some make the change from childhood into adolescence with only a few minor problems, others however, have a more difficult time handling these pressures and some may develop eating disorders as a way to cope. Some may enter into puberty early and be subjected to teasing by their peers. Much fear is of the weight that is gained during this time, and they desperately try to take the weight off. They think once they start losing weight, people might compliment them, which would make them feel good. They may start to belive that losing weight will make them happier, but no matter how much weight is lost, it's never enough, and they are never happy.

The adolescent girls have an intense fear of weight gain despite the fact they are either of normal weight or under weight. Today many adolescent girls and women believe that the only way to feel attractive and beautiful is to have bodies which consist of nothing but skin and bones.

Similarly in our study we found that $42 \%$ of the cases thought that it was important for them to be thinner, $56 \%$ didn't think so and $2 \%$ occasionally thought so. Among the sample of 100 students $22 \%$ resorted to various appetite control measures while as $78 \%$ didn't. $12 \%$ of cases skipped their meals in order to control their body weight, $80 \%$ didn't skip their meals, $7 \%$ occasionally did so and $1 \%$ was not sure. It indicated that many of the cases were body conscious and adopted various measures to regulate body weight. Social and cultural expectations encourage adolescent girls to be thin. Such pressures sometimes lead to emotional disorders.

Dieting is the highest risk factor for triggering an eating disorder. The severe dieters are 18 times more likely to develop an eating disorder than those who don't diet. It is often during adolescence that young females become aware of the concept of dieting, often through parents, peers and the images set by the media which correlate thinness with beauty and popoularity.

In our study only $11 \%$ of respondents liked to diet so as to have control over body wieght, $83 \%$ didn't diet and 6\% occasionally resorted to dieting. It was most (33.3\%) prevalent in 18-19 year age group followed by $12 \%$ in 14-15 years age groups. Among different family income groups it was most (20\%) prevalent in above Rs.50,000 family income, followed by $15.4 \%$ in below Rs. 10,000 . Respondents whose father's qualification was professional reported the highest. Lower mother's qualificatin groups showed higher percentage (16.7\%) in below matric group. Also $35 \%$ of the cases planned to exercise if they gained extra weight, $58 \%$ didn't, $6 \%$ occasionally thought so and $1 \%$ was not sure.

Study on dieting in adolescence by Richard et al (2003) has consistently shown a high prevalence of dieting, about $60 \%$ to $80 \%$ since the early 70 's. Among the 9 year olds, $31 \%$ thought themselves too fat and almost half were on a diet.

The results from our study say $19 \%$ of the sample felt worthless, hopeless and that people judged them in a negative way and $27 \%$ of them occasionally had such feelings, while $53 \%$ had no such feelings and $1 \%$ was not sure.

Research on body image suggests that from an early age, girls begin to understand cultural messages about thinness as measures of physical attractiveness, social accceptance, and happiness. It also appears the influence of these messages does not diminish as women move through the life span. Dissatisfaction with body size and shape is so prevalent in girls and women that it has been described to have serious implications on women's health in the form of body distortion, disordered eating, low self-esteem, and depression (Tiggeman \& Lynch, 2001). Overall research indicates that $90 \%$ of women are dissastisfied with their appearance in some way.

The influence of models and actresses on the appearance of the our sample is quite apparent, as $45 \%$ of the respondents disclosed that they liked to compare their bodies with actors and wished to be thin and good looking like them.

Recent studies have provided convincing evidence that media images play a signifidcant role in how women feel about their bodies. Teenagers are belielved to be among the heaviest users of many forms of mass media, particularly magazines and television. Research has revealed that women do feel more guilty, anxiuos, and depressed after viewing thin models in the media (Hoyt and Kogan, 2001).

As a result adolescents constantly feel themselves under pressure. The results obtained in our study indicate that $8 \%$ of cases ate to escape their worries $89 \%$ didn't, $3 \%$ occasionally ate to escape worries. $19 \%$ of the sample felt worthless, hopeless and that people judged them in a negative way and $27 \%$ of them occasinally had such feelings while 53\% had no such feelings and $1 \%$ was not sure. The results also revealed that $66 \%$ of the cases suffered from depression, hopelessness or found it hard to handle their problems.

The correlations between the desire to be thinner than friends and age group, fathers and mothers qualification, and family indcome was statistically significant, at 0.05 level of significance. In our sample, $35 \%$ registered that they would exercise if they gained weight and 58\% didn't want to exercise even if the weight was 
gained while as $6 \%$ occasionally thought to exercise in case they gained weight and $1 \%$ of the sample was not sure.

Also $80 \%$ of the respondents did not skip their meals to control weight however $12 \%$ of them resort to skipping meals as an attempt to control weight, $7 \%$ occasionally skipped their meals to control their weight and $1 \%$ was not sure. On the basis of the results obtained it is deduced that $22 \%$ of the students controlled their appetite by one or the other methods like by eating junk foods, candies, gums or by drinking lots of water and coffee and $78 \%$ of the students didn't do such things to control their appetite. $6 \%$ of the cases had abnormal eating practices and used to hide them. $91 \%$ didn't plan secret eating while as $3 \%$ occasionally did so. $8 \%$ had cravings to eat snacks when they woke up at night, while as $84 \%$ cases had no such urges or cravings. Just $1 \%$ of the adolescent resorted to self induced vomiting after eating, $19 \%$ occasionally did so while as $79 \%$ didn't vomit after eating and $1 \%$ of the respondent was not sure. $11 \%$ of the sample replied that they diet to reduce weight $6 \%$ occasionally did so while as $83 \%$ never diet to reduce their weight.

According to Massey-Stokes (2000), over one-third of adolescent females report paraticipating in injurious methods of weight maintenance, which is further evident that this age group desires to live up to the idealized "thinness" revered by society.

In this study, middle family income groups showed higher percentage of disliking for one's body, comparing oneself with actors and models and lack of control over eating. Higher income groups showed higher percentage of eating binges. Dieting as a way to control weight was equally prevalent in both highest and lowest income groups. In all above cases correlation was statistically insignificant. However a statistically significant correlation was found between family income and importance of being thinner than one's friends with lower income groups showing higher percentage. Lowest income group i.e. <Rs.10,000 showed highest percentage of $84.6 \%$ followed by $45.5 \%$ in Rs.20,000-30,000 group. Thus an accurate relation has not been detected between the frequency of eating disorder and the family income. This result can be explained by the fact that the students studying in different schools from different socio-economic backgrounds didn't represent a serious case of disorder as far as their income was considered.

\section{Conclusion}

In our study, we conclude that none of the adolescent girls satisfied all the criteria necessary for diagnosis of anorexia nervosa or bulimia nervosa as far as DSM-IV criteria are concerned. However, most of the girls had one or two of the four criteria's as mentioned in DSM-IV of either anorexia or bulimia nervosa. Six percent of them even satisfied upto three criteris's. Although the prevalence of the eating disorders is very less in our city but the adolescent girls are becoming body conscious.

A substantial percentage of them have distorted body image and low self esteem. Many of the adolescent girls are at high risk of developing eating disorders. It seems to be right time to take preventive measures. Health education seems to be the best way to counter this problem. People in general and adolescent girls and their parents in particular should be taught about eating disorders, its signs and symptoms and its disastrous sonsequences. Adolescent girls should be educated about normal weight for age. Parents should keep watch on wrong dietary habits of their children. They should not have unattainable expectations from their children. They should support them during periods of stress. The family environment can also have a major role to control the problems of eating disorder. Proper dietary habits and routine exercise can lower the risk fo eating disorders. Timely medical advice should be sought in case of any suspicion of any eating disorder. Media can play an important role in educating the common people.

\section{References}

[1] Alantar, Z. (2008), Eating disorders in the context of attachment theory, Anatolian Journal of Psychiatry (Anadolu Psikiyatri Dergisi), vol 9(2).pp97-104

[2] Garner DM, Garfinkel PE, O' Shaughnessy. (1985). The Validity of the distinction between bulimia with and without anorexia nervosa Am J Psychiatry, 142(5):581-7.

[3] Grigg M, Bowman J, Redman S (2002). The disordered eating and unhealthy weight reduction practices among adolescent females, Med J. 95(9):1032.

[4] Hoyt, W. D., \& Kogan, L. R. (2001). Satisfaction with body image and peer relationships for males and females in a college environment. Sex Roles, 45, 199-215.

[5] Kaltiala-Heino R, Rissanen A, Rimpela M, Rantanen P, Encephale (1989). Bulimia and Bulimic behaviour in middle adolescnece: more common tha thought Acta Psychiatr Scand, Jul; 1009-10:33-9.

[6] Killen et al, Risk factor for the developmetn of eating disorders, Ministry of Health New Zealand 1998 in eating disorders Review Part I (Stephen Wonderich Janes E, Radcliffe Publishing Page.73)

[7] Lowe SG, Miles SW, Richards CG. (1985) Eating Attitudes in an Adolescnet School Girl Population, New Zealand Medican Journal, 330-331.

[8] Mammen P, Russel S, Russel PS (2007). Prevalence of Eating Disorders ad Psychiatric Co-Morbidity among Children and Adolescents, Indian Pediatrics , (44), 357-359.

[9] Massey-Stokes (2000), Contemporary Issues in Education Research, 1(260).

[10] Neumark-Sztainer D, Wall M, Guo J, Story M, Haines J, Eisenberg M (2006). The Obesity, disordered eating and eating disorders, J Am Diet Assoc 106(4):523-5. 
[11] Richards et al., (2003). Dieting in Adolescence, International Journal of Obesity, 27.404-409.

[12] Ruth H.S., Timothy, J.N and William V.T., Diabetes Care, 1992.Vol.15 No.10 Pages: 1361-1368.

[13] Sidhu A, Older Children and Adolescents (MFN-04 Advance Nutrition IGNOU, Page No. 471-474, 2006).

[14] Sonja I, Swanson SC, Scott M, Crow J, Daniel Le Grange MD, Swendsen J, Kathleen R (2011). Merikangas, Archives of General Psychiatry, Prevalence and Correlates of Eating Disorders in Adolescents, 68(7), 714-723.

[15] Stuart \& Laria. (2001). The Management of Eating Disorders and Obesity (Principles and Practice of Psychiatric Nursing, $526-527$.

[16] Tiggemann M \& lynch JE (2001). Body Image across the Life Span in adult Women: the role of self objection. Dev Psycho. $37(2): 243-53$. 